\title{
FABRICATION AND CRYSTAL STRUCTURE OF SOL-GEL DEPOSITED BST THIN FILMS WITH COMPOSITIONAL GRADIENT
}

\begin{abstract}
In the present research technology of compositionally graded barium strontium titanate $\mathrm{Ba}_{1-\mathrm{x}} \mathrm{Sr}_{\mathrm{x}} \mathrm{TiO}_{3}$ thin films deposited on stainless steel substrates by sol-gel spin coating followed with thermal annealing at $T=650^{\circ} \mathrm{C}$ is reported. Results of thermal behavior of the sol-gel derived powders with compositions used for fabrication of graded structure (i.e. with Sr mole fraction $x=$ $0.5,0.4$ and 0.3 ) are described. X-ray diffraction studies of the phase composition and crystal structure of such complex thin film configuration are given. It was found that gel powders exhibited a large total weight loss of about $\Delta m \approx 44-47 \%$. Three stages of weight loss took place at temperature ranges: below $T \approx 300^{\circ} \mathrm{C}$, at $\Delta T \approx 300-500^{\circ} \mathrm{C}$ and between $T=600^{\circ} \mathrm{C}$ and $T=800^{\circ} \mathrm{C}$. Phase analysis has shown that the dominating phase is $\mathrm{Ba}_{0.67} \mathrm{Sr}_{0.33} \mathrm{TiO}_{3}$ compound while the second phase is $\mathrm{Ba}_{0.7} \mathrm{Sr}_{0.3} \mathrm{TiO}_{3} \mathrm{Or}_{\mathrm{Ba}_{0.5}} \mathrm{Sr}_{0.5} \mathrm{TiO}_{3}$ for "up-graded" and "down-graded" structure, respectively.

Keywords: $\mathrm{Ba}_{1-\mathrm{x}} \mathrm{Sr}_{\mathrm{x}} \mathrm{TiO}_{3}$ thin films; compositionally graded structure; sol-gel method; simultaneous thermal analysis; X-ray diffraction
\end{abstract}

\section{Introduction}

Functionally graded materials (FGM) are advanced engineering materials designed for a specific performance or function in which a spatial gradation in structure and/or composition lend itself to tailored properties. This occurs by providing in-depth graded compositions, microstructures and properties [1,2].

The scientific term "functionally graded material" was first introduced by a group of Japanese scientists [3,4]. Introducing compositional gradients has proven to be an effective method, for instance, in impeding crack propagation in structural components, enabled by elastic interactions between layers of different composition. This has led to significant improvements in areas such as the aerospace propulsion industry where functionally graded materials are employed as thermal barrier coatings in turbine blades to extend their lifetime [5].

In recent years modern synthesis and fabrication methods of compositionally graded materials have been developed $[1,6]$. This includes gas based, liquid phase and solid phase methods which can be used to physically or chemically obtain tailored properties. The ability to produce various functional materials (e.g. piezoelectric ceramics, thermoelectric semiconductors and biomaterials) that fulfill a specific functionality or exhibit particular properties making them suitable candidates for numerous high-tech applications in e.g., aerospace, nuclear industries or bioengineering [2,5] has escalated an interest in FGM recently.

In the last years, the attention of researchers has been focused on the barium strontium titanate $\mathrm{Ba}_{1-\mathrm{x}} \mathrm{Sr}_{\mathrm{x}} \mathrm{TiO}_{3}$ (BST) thin film considered as one important kind of compositionally graded materials. Because of high relative dielectric constant, low dielectric loss, high dielectric breakdown strength, high pyroelectric coefficient and good dielectric tunability, BST seems to be the material of choice for application in microelectronic devices such as high-density dynamic random access memories, pyroelectric infrared, detector and microwave devices [7,8].

Electrostatic interactions between ferroelectric layers with differing Curie temperatures can be employed to adjust properties of these systems and may even allow additional functionalities not found in any of the compositions comprising the structure. In BST-based thin film devices high electric fields and reasonable tunability may be achieved at room temperature at relatively low de voltages [7].

Goal of the present research was (i) to adopt the idea of functionally graded materials (FGM), (ii) to fabricate spatially inhomogeneous $\mathrm{Ba}_{1-\mathrm{x}} \mathrm{Sr}_{\mathrm{x}} \mathrm{TiO}_{3}$ thin films exhibiting artificial gradients in composition and (iii) to study phase composition and crystal structure of such graded films by X-ray diffraction method.

\footnotetext{
* UNIVERSITY OF SILESIA IN KATOWICE, INSTITUTE OF TECHNOLOGY AND MECHATRONICS, 12 ŻYTNIA STR., 41-200 SOSNOWIEC, POLAND

** UNIVERSITY OF APPLIED SCIENCES MÜNSTER, DEPARTMENT OF CHEMICAL ENGINEERING, STEGERWALDSTRASSE 39, D-48565, STEINFURT, GERMANY

\# Corresponding author: dionizy.czekaj@us.edu.pl
} 


\section{Thin film deposition route}

For the purpose of the present study the graded $\mathrm{Ba}_{1-x} \mathrm{Sr}_{x} \mathrm{TiO}_{3}$ (BST) thin films with a compositional step-variation normal to the substrate were fabricated. To form compositionally graded BST thin films by sol-gel method the precursor solutions utilized were as follows: $\mathrm{Ba}_{0.5} \mathrm{Sr}_{0.5} \mathrm{TiO}_{3}, \mathrm{Ba}_{0.6} \mathrm{Sr}_{0.4} \mathrm{TiO}_{3}$, and $\mathrm{Ba}_{0.7} \mathrm{Sr}_{0.3} \mathrm{TiO}_{3}$, respectively. To prepare precursor solutions barium acetate $\left(\mathrm{Ba}\left(\mathrm{CH}_{3} \mathrm{COO}\right)_{2}, 99 \%\right)$, strontium acetate $\left(\mathrm{Sr}\left(\mathrm{CH}_{3} \mathrm{COO}\right)_{2}, 99 \%\right)$, and tetra-butyl titanate $\left(\mathrm{Ti}\left(\mathrm{OC}_{4} \mathrm{H}_{9}\right)_{4}, 97 \%\right)$ were used as starting materials. Glacial acetic acid $\left(\mathrm{CH}_{3} \mathrm{COOH}\right)$ was used as a catalyst, whereas $n$-butanol $\left(\mathrm{CH}_{3}\left(\mathrm{CH}_{2}\right)_{3} \mathrm{OH}\right)$ was used as a solvent. All above reagents were of analytic purity.

After stoichiometrically dissolved, mixed and stirred the precursor solution was deposited by spin coating (KW-4 type spin-coater by Chemat Technology Inc.) on polished stainless steel substrates (AISI 304 type). Spin coating was performed at $\omega=3500$ revolution per $\min$ for $t=30 \mathrm{~s}$. Due to accumulation of particles in liquid layer the wet films were formed. The wet films were given a heat treatment at $T=150^{\circ} \mathrm{C}$ for $t=5 \mathrm{~min}$. As a result of drying evaporation of solvent and volatile products occurred. After removal of $\mathrm{H}_{2} \mathrm{O}$, the films were subjected to pyrolysis at $T=350^{\circ} \mathrm{C}$ for $t=5 \mathrm{~min}$. Due to removal of covalently bond organics inorganic thin films were formed. The coating process was repeated up to 15 or 30 times thus yielding thin films of $d=300 \mathrm{~nm}$ or $d=600 \mathrm{~nm}$ in thickness, respectively. Fig. 1 shows the steps of the thin film growth process. The graded structure was formed by spin-coating of the successive layers with Sr mole fraction $x$ ranging from $x=0.5$ to $x=0.3$.

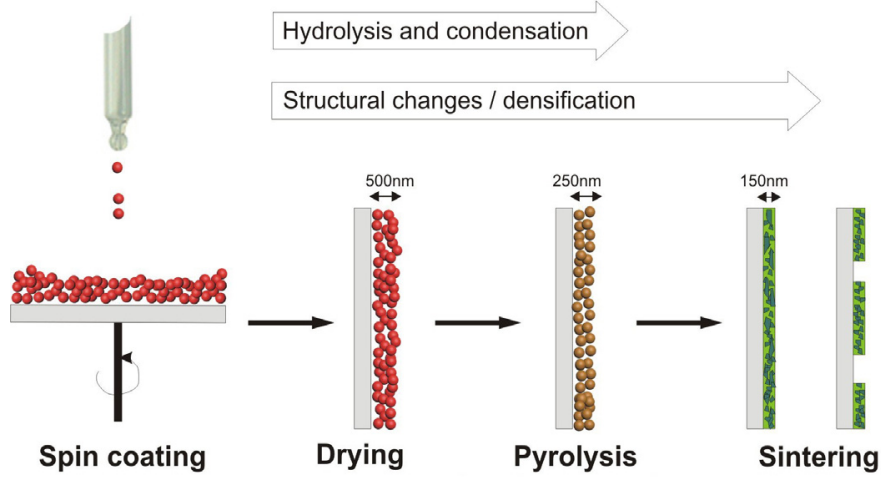

Fig. 1. Sol-gel thin films - steps of a film formation

The graded structure was formed by spin-coating of the successive layers with $\mathrm{Sr}$ mole fraction $x$ ranging from $x=0.5$ to $x=0.3$ (constitutive gradation; Fig. 2).

After deposition of the spatially inhomogeneous structure the process of transformation of as - deposited BST thin films into polycrystalline films was performed by conventional furnace annealing in an ambient atmosphere at $T=650^{\circ} \mathrm{C}$ for $t=2$ hours (the heating rate was $2^{\circ} \mathrm{C} / \mathrm{min}$ ).

For convenience, the graded films starting with the $\mathrm{Ba}_{0.7} \mathrm{Sr}_{0.3} \mathrm{TiO}_{3}$ layer at the film - substrate interface and with a $\mathrm{Ba}_{0.5} \mathrm{Sr}_{0.5} \mathrm{TiO}_{3}$ layer at the top surface are called "down -

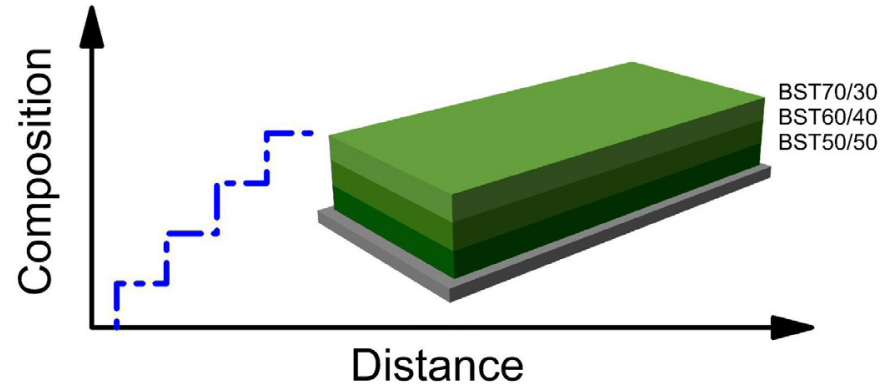

Fig. 2. Schematic structure of the stepwise gradient of the chemical composition and fabricated "up - graded" (BST567) thin film

graded" (or BST765) films, whereas the films with the opposite compositional gradient are called "up - graded" (or BST567) films [7].

\section{Results and discussion}

\subsection{Thermal analysis of BST dried gel}

Differential thermal analysis (DTA) and thermogravimetric analysis (TG/DTG) were used to determine the thermochemical properties of BST7030, BST6040 and BST5050 dried gel powders. Simultaneous measurements were executed by heating the dried powders in air at $10^{\circ} \mathrm{C} / \mathrm{min}$, to $1300^{\circ} \mathrm{C}$. Netzsch STA -409 thermal analyzer was utilized for the studies.

Results of thermal gravimetric analysis (TG) and differential thermal analysis (DTA) performed for dried gel powders of BST7030, BST6040 and BST5050 are shown in Fig. 3a,b, respectively. One can see from Fig. 3 that all dried gel powders exhibited a large total weight loss of $\Delta m \approx 44.12 \%$ for BST7030, $\Delta m \approx 47.03 \%$ for BST6040, and $\Delta m \approx 46.81 \%$ for BST5050. Moreover, the three stages of weight loss can be seen.

One can see (Fig. 3) that the first drop of the thermogravometric (TG) curve occurs in the temperature range below $T \approx 300^{\circ} \mathrm{C}$. The endothermic peak at around $T=123.8^{\circ} \mathrm{C}$ and corresponding weight loss $\Delta m_{1} \approx 16 \%$ for BST7030 on the TG curve, $T=124.9^{\circ} \mathrm{C}$ and corresponding weight loss $\Delta m_{1} \approx 15 \%$ for BST6040 and $T=125.2^{\circ} \mathrm{C}$ and corresponding weight loss $\Delta m_{1} \approx 18 \%$ for BST5050 on the TG curve, are due to the evaporation of solvents.

The second notable weight loss was detected within the temperature range $\Delta T \approx 300-500^{\circ} \mathrm{C}$. In case of BST7030 the weight loss of $\Delta m_{2} \approx 26 \%$ at $T \approx 334^{\circ} \mathrm{C}$ was detected, whereas for BST6040 the weight loss of $\Delta m_{2} \approx 21 \%$ was detected at $T \approx 337^{\circ} \mathrm{C}$ and the weight loss of $\Delta m_{2} \approx 19.6 \%$ was detected at $T » 340^{\circ} \mathrm{C}$ for BST5050. It is worth noting, that this second drop on a TG curve matches a large exothermic peak in the DTA curve. Since no crystallization takes place below $T=500^{\circ} \mathrm{C}$, the weight loss is probably due to the decomposition of organic additives in the gel.

The exothermic peak around $T \approx 400^{\circ} \mathrm{C}$ and relatively broad exothermic features within the temperature range $\Delta T \approx 650-700^{\circ} \mathrm{C}$ for all dried gels, could be due to crystallization of various inter- 


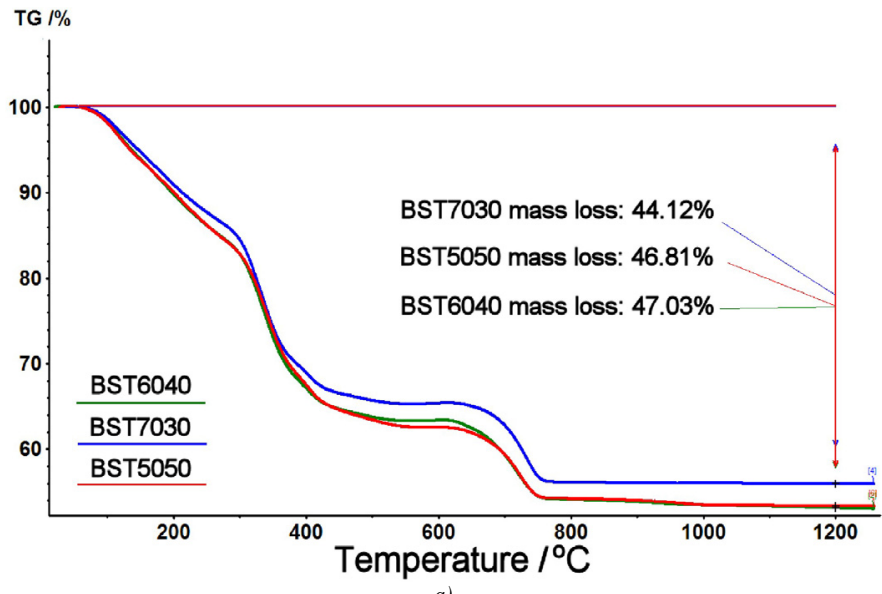

a)

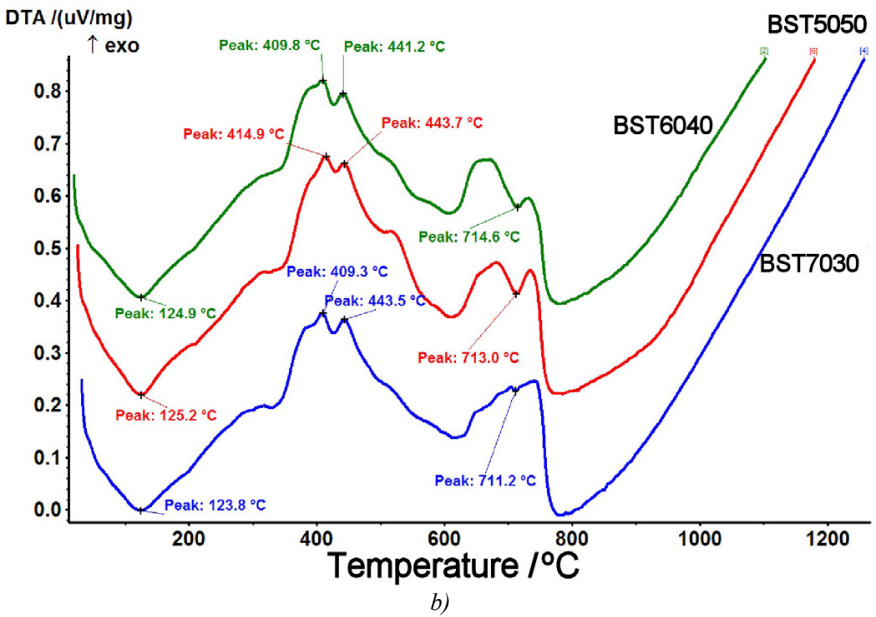

Fig. 3. Results of thermogravimetry $(a)$ and differential thermal analysis (b) of BST7030 BST6040 and BST5050 dry gel mediate phases. It is known that for sol-gel derived barium titanate several intermediate phases form prior to the transformation of the amorphous phase into the perovskite phase. The nature of these intermediate phases and the crystallization sequence depends upon the precursors used [9].

The third notable drop between $T=600^{\circ} \mathrm{C}$ and $T \approx 750^{\circ} \mathrm{C}$ corresponds to a peak on the DTA curve at about $T=718.5^{\circ} \mathrm{C}$. From the XRD measurements the growth of perovskite BST was ascertained. The weight loss originates from the release of various side products during alcoxylation (i.e. removal of $\mathrm{H}$ as an alcohol) and oxolation (i.e. removal of $\mathrm{H}$ as water).

Above $T \approx 750^{\circ} \mathrm{C}$ there was no more weight loss. A further increase in the temperature promotes crystallization of BST, but no new chemical reactions take place.

\subsection{X-ray phase analysis of graded BST thin films}

X-ray diffraction patterns of BST thin films were collected at room temperature (XPert-Pro diffractometer, $\Theta-2 \Theta$ mode, CoK $\alpha$ radiation, detector scan step size $\Delta 2 \Theta=0.01^{\circ}$, scan type continuous, scan step time $t=6-7 \mathrm{~s}$, and the data angle range $\Delta 2 \Theta=10-105^{\circ}$ ). Phase analysis of X-ray diffraction patterns was carried out using Match! (Crystal Impact) computer program [10]. Results are shown in Fig. 4 and Fig. 5 for up-graded and down-graded BST thin films, respectively.

Visual inspection showed that both diffraction patterns are similar. One can see three groups of diffraction lines coming from the stainless steel substrate (iron nickel) at diffraction angles $2 \Theta \approx 51^{\circ}, 59.7^{\circ}$ and $89.5^{\circ}$. Semi-quantitative analysis based

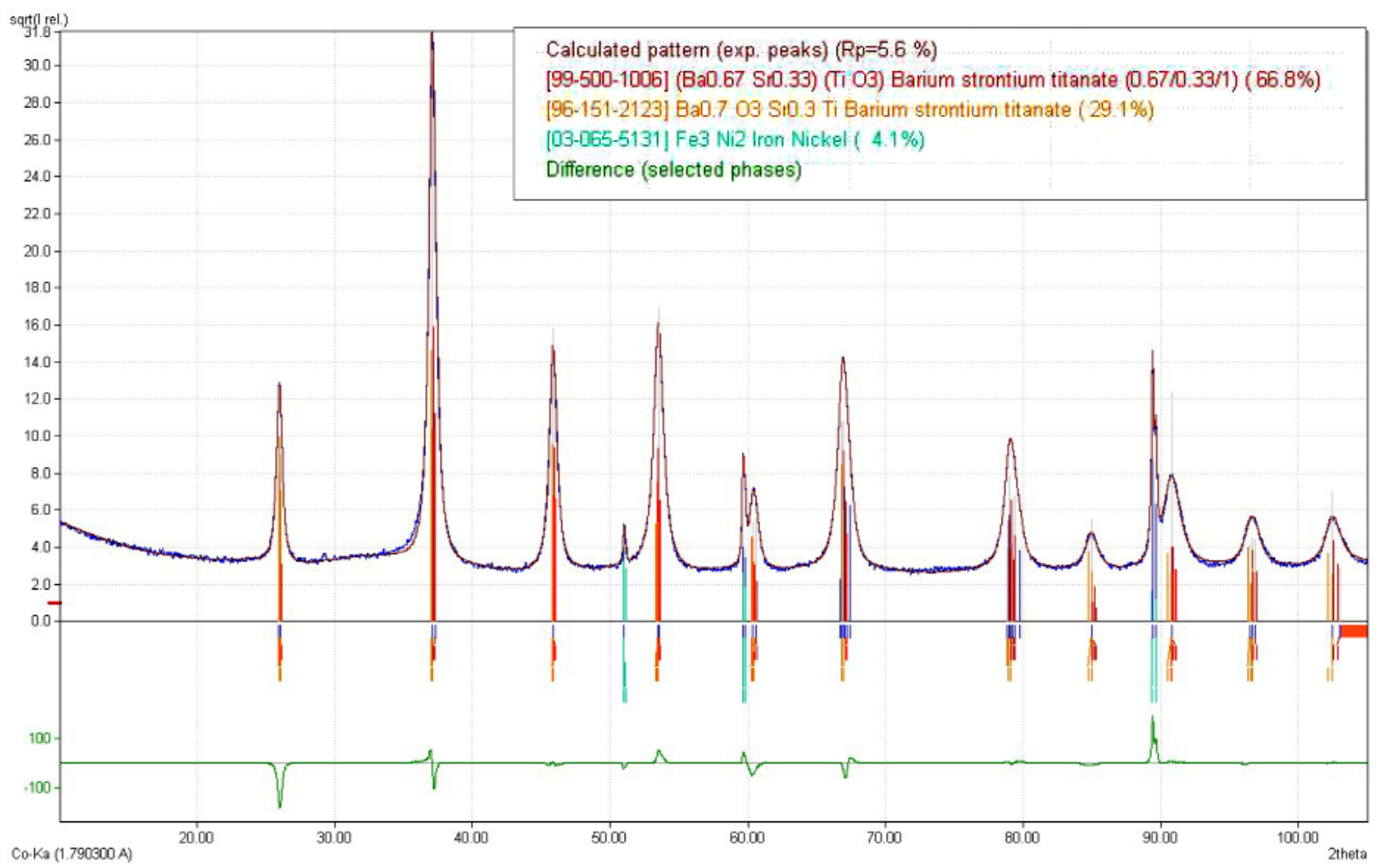

Fig. 4. X-ray diffraction pattern of BST567 on stainless steel 


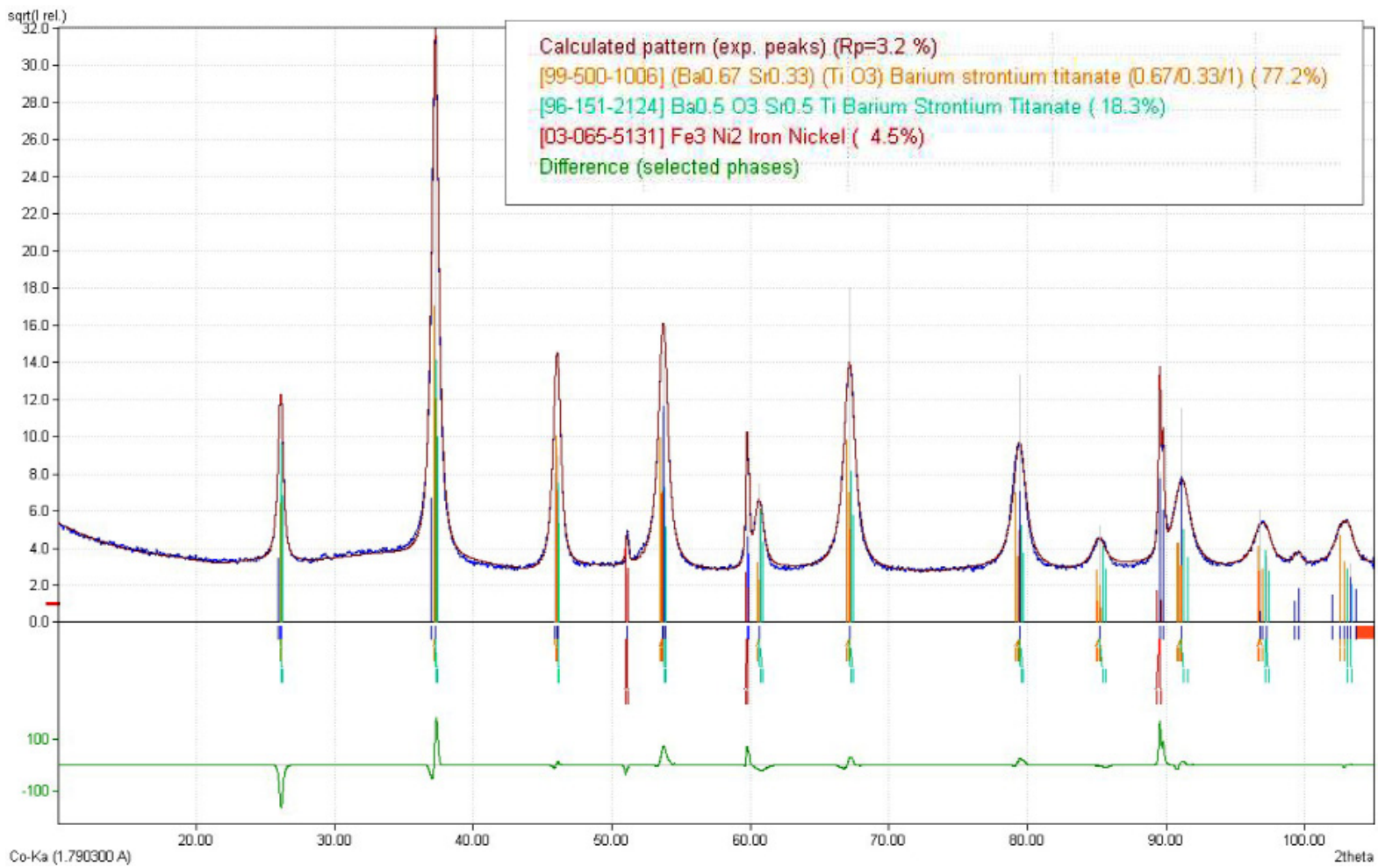

Fig. 5. X-ray diffraction pattern of BST765 on stainless steel

on the reference intensity ratio method [11] made it possible to evaluate contribution of the most likely BST-based phases into the total diffraction pattern. Results of the calculations are given in Table 1.

TABLE 1

Results of semi-quantitative analysis of the phase composition of BST thin films annealed at $T=650^{\circ} \mathrm{C}$

\begin{tabular}{|l|c|c|}
\hline \multicolumn{1}{|c|}{ Phase composition } & BST567 & BST765 \\
\hline Iron nickel substrate, [\%] & 4.1 & 4.5 \\
\hline $\mathrm{Ba}_{0.67} \mathrm{Sr}_{0.33} \mathrm{TiO}_{3},[\%]$ & 66.8 & 77.2 \\
\hline $\mathrm{Ba}_{0.7} \mathrm{Sr}_{0.3} \mathrm{TiO}_{3},[\%]$ & 29.1 & - \\
\hline $\mathrm{Ba}_{0.5} \mathrm{Sr}_{0.5} \mathrm{TiO}_{3},[\%]$ & - & 18.3 \\
\hline
\end{tabular}

One can see that major phase of both graded structures is composition $\mathrm{Ba}_{0.67} \mathrm{Sr}_{0.33} \mathrm{TiO}_{3}$ (ICSD pattern code 54150; Figureof-Merit, i.e. a number which is calculated from the various measures of agreement between database and unknown pattern, $F o M=0.874$ and $F o M=0.792$ for BST567 and BST765, respectively).

The bottom layer of both graded structures (i.e. $\mathrm{Ba}_{0.5} \mathrm{Sr}_{0.5} \mathrm{TiO}_{3}$ in case of BST567 and $\mathrm{Ba}_{0.7} \mathrm{Sr}_{0.3} \mathrm{TiO}_{3}$, in case of BST765) is "not detectable" by applied geometry of X-ray diffraction studies. On the other hand the upper layer of both up- and down-graded structures is "present" in the diffraction pattern. Influence of the stainless steel substrate was evaluated as 4.1-4.5 mass \% (iron nickel, cubic structure, $F m-3 m$ (225) space group; $a=3.598 \AA$; PDF card No 03-065-5131).

\subsection{X-ray structural analysis}

The structural analysis was performed with X'pert HighScore Plus software (PANalytical B.V). The latest available ICSD [12], ICDD [13] and COD[14], databases were utilized. Refinement of the structural parameters of BST-based phases was performed with the Rietveld method [15]

According to the results of phase analysis (Table 1) the main phase that constituted BST graded thin film is $\mathrm{Ba}_{0.67} \mathrm{Sr}_{0.33}$ $\mathrm{TiO}_{3}$ phase. Therefore for the Rietveld refinement only the $\mathrm{Ba}_{0.67} \mathrm{Sr}_{0.33} \mathrm{TiO}_{3}$ phase and substrate were taken into consideration. Results of the analysis are shown in Fig. 6 and Fig. 7. Global and structural parameters of the analysis are shown in Table 2 and Table 3 , respectively.

TABLE 2

Global parameters of the Rietveld analysis

\begin{tabular}{|l|c|c|}
\hline \hline \multicolumn{1}{|c|}{ Parameter } & BST567 & BST765 \\
\hline Profile function: & \multicolumn{2}{|c|}{ Pseudo Voigt } \\
\hline Background: & \multicolumn{2}{|c|}{ Polynomial } \\
\hline R (expected); \%: & 10.35 & 9.58 \\
\hline R (profile); \%: & 15.35 & 15.53 \\
\hline R (weighted profile); \%: & 23.14 & 23.12 \\
\hline GOF: & 4.99 & 5.83 \\
\hline
\end{tabular}

On the base of the structural analysis of BST thin films one can see that there is a small difference in the lattice parameters of the dominating BST phase between BST567 and BST765 thin films. However, as it results from numerical studies [e.g. $8,16]$, there is a very wide spectrum of electronic, electrical, and 
Counts
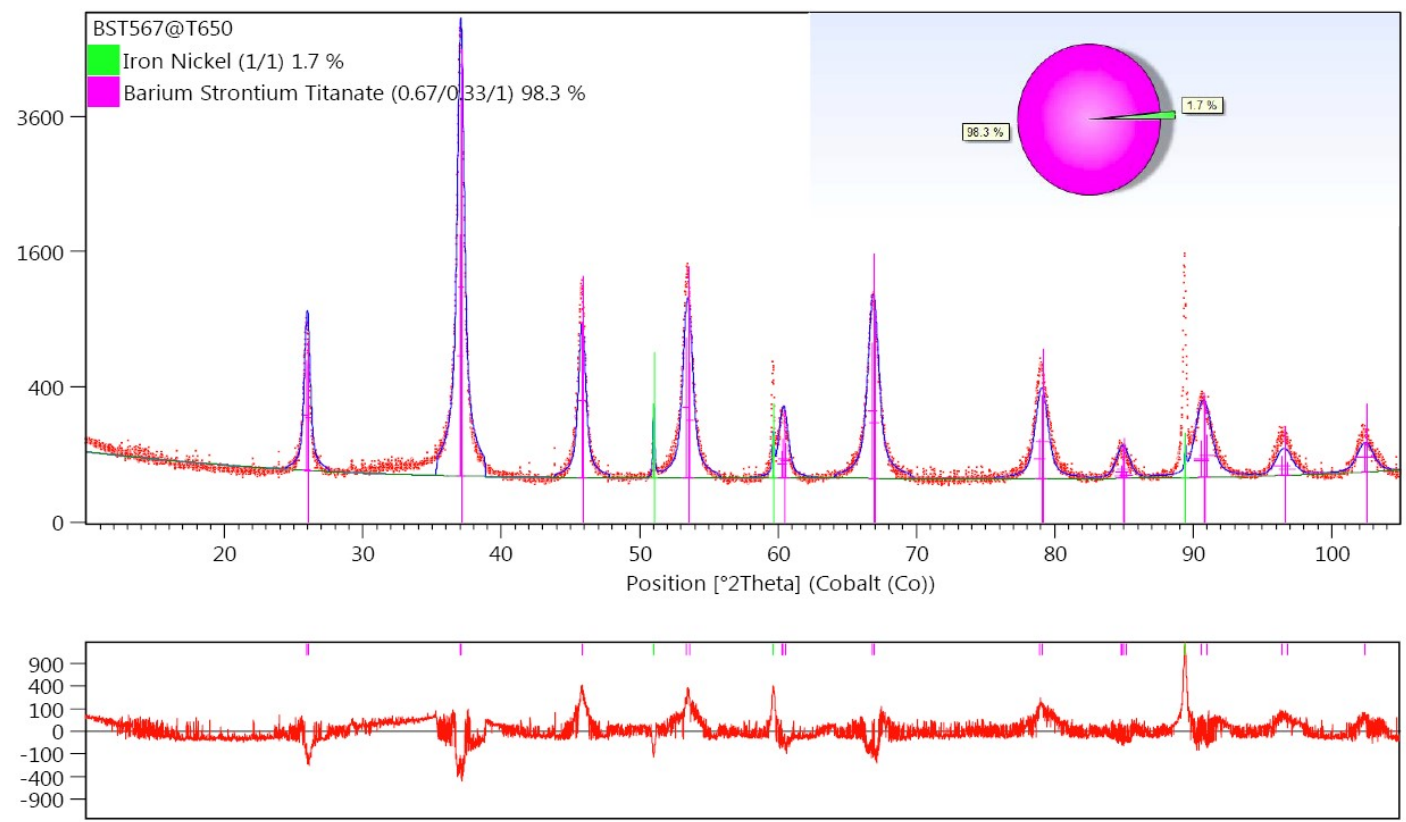

Fig. 6. Results of the structural analysis and refinement of elementary cell parameters for BST567 thin film deposited on stainless steel. Bottom plot shows the difference between the experimental and calculated patterns

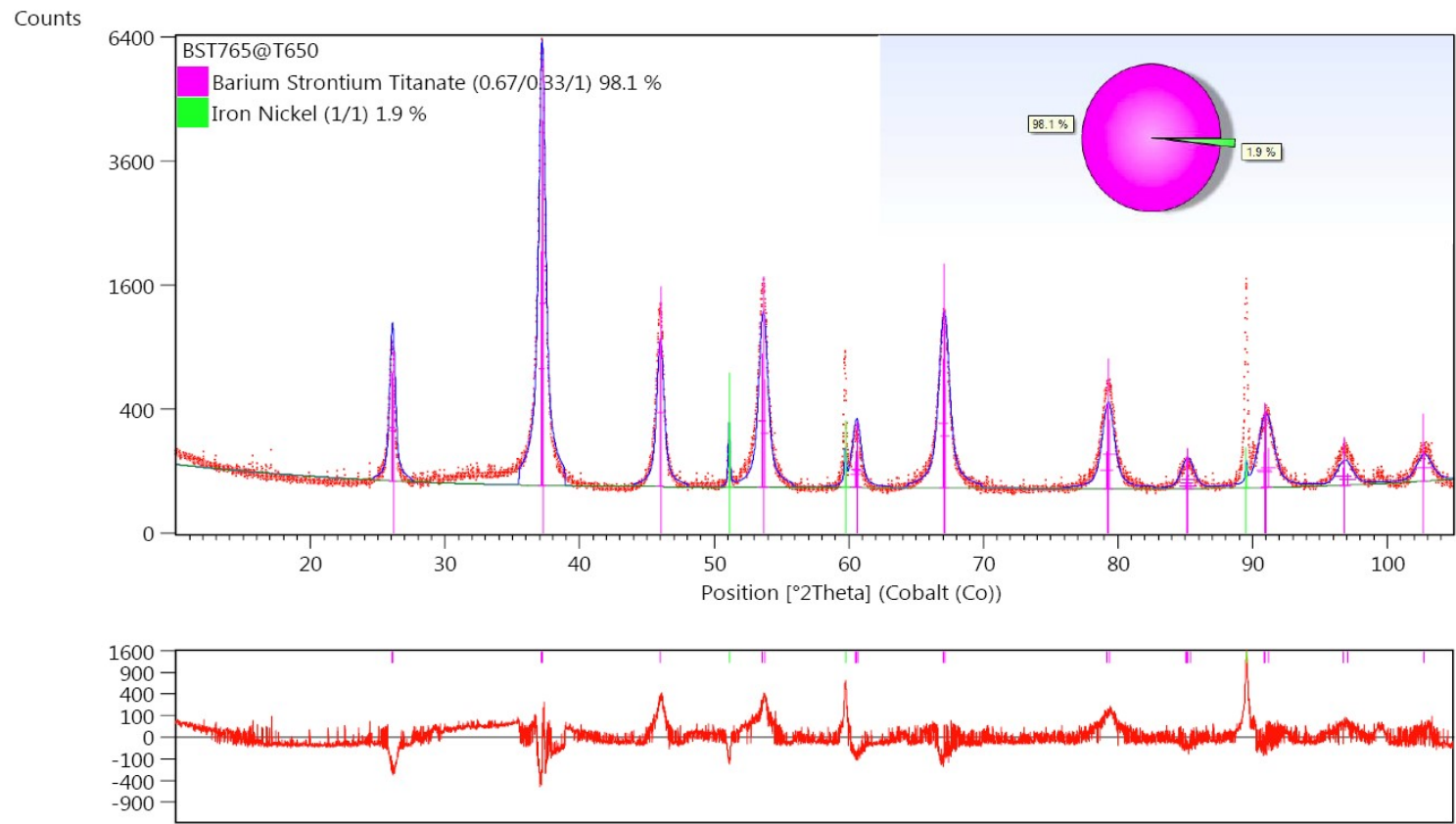

Fig. 7. Results of the structural analysis and refinement of elementary cell parameters for BST765 thin film deposited on stainless steel. Bottom plot shows the difference between the experimental and calculated patterns

TABLE 3 dielectric properties that can be expected from composition-

Structural parameters of the $\mathrm{Ba}_{0.67} \mathrm{Sr}_{0.33} \mathrm{TiO}_{3}$ phase

\begin{tabular}{|c|c|c|}
\hline \multicolumn{1}{|c|}{ Relevant parameters } & BST567 & BST765 \\
\hline Weight fraction / \%: & 98.34 & 98.14 \\
\hline Space group (No.): & $\mathrm{P} 4 \mathrm{~m} \mathrm{~m}(99)$ & $\mathrm{P} 4 \mathrm{~m} \mathrm{~m}(99)$ \\
\hline Lattice parameters: & & \\
\hline $\mathrm{a} / \AA$ & $3.978(6)$ & $3.970(6)$ \\
\hline $\mathrm{b} / \AA:$ & $3.978(6)$ & $3.970(6)$ \\
\hline $\mathrm{c} / \AA:$ & $3.963(2)$ & $3.957(9)$ \\
\hline $\mathrm{V} / 10^{6} \mathrm{pm}^{3}$ & 62.74 & 62.39 \\
\hline
\end{tabular}

ally graded heterostructures. Therefore, it is difficult to devise a straightforward approach to correlate the dielectric response to a particular set of interrelated material parameters and boundary conditions such as layer thickness, top/bottom electrode asymmetry and extrinsic effects. Compositional variations in ferroelectrics generate strong internal long-range (volumetric) electric fields which are responsible for unique hysteresis response and dielectric, piezoelectric, and pyroelectric properties [7,8]. Such interactions, can be quite complex as the system minimizes the 
total free energy via making adjustments to polarization in the presence of coupled tensorial property coefficients of various ranks [16].

Authors realize, that inherent complexities related to electrostatic interactions in graded BST thin films make it difficult for intuitive experimental approaches in design of such systems with desired functionalities. Nevertheless, these materials are ideally suited for systematic materials-by-design concepts guided by theoretical methods.

\section{Conclusions}

Compositionally graded $\mathrm{Ba}_{1-\mathrm{x}} \mathrm{Sr}_{\mathrm{x}} \mathrm{TiO}_{3}$ thin films with $x$ decreasing from 0.5 to 0.3 were successfully deposited by sol-gel spin coating method. Both up and down composition gradients with respect to the substrate were studied in terms of their phase composition and crystal structure. It was found that gel powders exhibited a large total weight loss of about $\Delta m \approx 44-47 \%$. Three stages of weight loss took place at temperature ranges: below $T \approx 300^{\circ} \mathrm{C}$, at $\Delta T \approx 300-500^{\circ} \mathrm{C}$ and between $T=600^{\circ} \mathrm{C}$ and $T=800^{\circ} \mathrm{C}$. Phase analysis has shown that the dominating phase is $\mathrm{Ba}_{0.67} \mathrm{Sr}_{0.33} \mathrm{TiO}_{3}$ compound. According to the Rietveld analysis performed in assumption of the dominating phase it was found that weight fraction of the iron nickel (substrate) was only $1.7-1.9 \%$. Also a small difference was found in the lattice parameters of the dominating BST phase between BST567 and BST765 thin films. Calculated density was 5.738 and $5.770 \mathrm{~g} / \mathrm{cm}^{3}$ for up- and down-graded BST films, respectively.

\section{Acknowledgements}

Contribution of Dr K.Osińska and Dr T. Orkisz in the thin film technology is greatly acknowledged.

\section{REFERENCES}

[1] M. Naebe, K. Shirvanimoghaddam, Applied Materials Today 5, 223-245 (2016).

[2] Miyamoto Y, Kaysser WA, Rabin BH, Kawasaki A, Ford RG. Functionally graded materials. Design, processing and applications.: 1999 Kluwer Academic Publishers, Dordrecht/Boston/ London.

[3] M. Niino, S. Maeda, Recent development status of functionally gradient materials. ISIJ International 30 (9), 699-703 (1990).

[4] M. Koizumi, Recent progress of functionally gradient materials in Japan. In: 16th annual conference on composites and advanced ceramic materials 13, 333 (1992).

[5] M. Koizumi, FGM activities in Japan, Composites B: Eng. 28, (1-2), 1-4 (1997).

[6 B. Kieback, A. Neubrand, H. Riedel, Processing techniques for functionally graded materials, Materials Science and Engineering A362, 81-105 (2003).

[7] D. Czekaj, Fabrication and study of BST-based functional materials, 2010 University of Silesia, Gnome Publishing House, Katowice.

[8] Y. Benhouria, I. Essaoudi, A. Ainane, R. Ahuja, F. Dujardin, Chinese Journal of Physics, 54, 533-544 (2016).

[9] S.B. Majumder, M. Jain, A. Martinez, R.S. Katiyar, F.W. Van Keuls, F.A. Miranda, J.Appl.Phys. 90, 896 (2001).

[10] MATCH! Version 2.4.5 CRYSTAL IMPACT, Postfach 1251, 53002 Bonn, Germany (URL: http://www.crystalimpact.com/ match).

[11] I.S. Yakimov, P.S. Dubinin, O.E. Piksina, Inorganic Materials 47, 15,1681 (2011).

[12] ISCD Database, FIZ Karlsruhe, (URL: http://www.fiz-karlsruhe. de).

[13 International Centre for Diffraction Data, 12 Campus Boulevard, Newton Square, PA 19073-3273 U.S.A.; (URL: http://www.icdd. com).

[14] IUCr/COD/AMCSD Database (URL.: http://www. crystalimpact. $\mathrm{com} / \mathrm{match} /$ ).

[15] H.M.Rietveld, Austr. J. Phys. 113-116 (1988).

[16] I.B. Misirlioglu, S.P. Alpay, Acta Materialia 122, 266-276 (2017). 